\title{
Parâmetros físico-químicos, tecnológicos, atividade antioxidante, conteúdo de fenólicos totais e carotenóides das farinhas dos frutos do jatobá-do-cerrado (Hymenaea stigonocarpa Mart. ex Hayne)
}

\author{
Antonio Carlos Pereira de Menezes Filho ${ }^{1 *}$, Madalena Arantes da Silva1, Adriano Vilela Pereira1, Josemar Gonçalves de \\ Oliveira Filho ${ }^{2}$, Carlos Frederico de Souza Castro ${ }^{1}$
}

${ }^{1}$ Instituto Federal Goiano, Campus Rio Verde. Rodovia Sul Goiana, km 01, Zona Rural, Rio Verde - GO, Brasil.

${ }^{2}$ Universidade Estadual Júlio de Mesquita Filho, UNESP/SP, Campus Araraquara - SP, Brasil.

Autor correspondente.E-mail: biologoesanitaristaambiental@gmail.com

\section{N F O A R T I C L E}

\section{Histórico do artigo}

Recebido: 17 de agosto de 2018

Aceito: 30 de abril de 2019

Palavras-chaves:

$D P P H$

Cor Sementes

\begin{abstract}
R E S U M O
O uso de frutos nativos do Cerrado vem ganhando destaque para o desenvolvimento de novos produtos farináceos que apresentam características importantes para saúde e propriedades do alimento desenvolvido. 0 objetivo deste trabalho foi avaliar as farinhas obtidas a partir da casca, arilo e semente do fruto de H. stigonocarpa, quanto às características físico-químicas, tecnológicas, antioxidantes, fenólica total e de carotenóides. Os resultados apresentaram boas características físico-químicas como teor de proteínas, carboidratos, lipídios, pectinas e minerais; tecnológicas apresentou boa colorimetria e formação de gel farináceo resistente e absorção de água e óleo; importante atividade antioxidante na redução do radical DPPH, presença de compostos fenólicos totais e de carotenóides. As farinhas do fruto de H. stigonocarpa apresentaram excelentes características que as tornam importantes no desenvolvimento de novos produtos alimentícios e farmacêutico, aliando a qualidade e a riqueza de compostos naturais importantes para a manutenção da qualidade de vida mais saudável, bem como garantir a preservação da espécie H. stigonocarpa no ambiente natural de Cerrado.
\end{abstract}

\section{Introdução}

O Hymenaea stigonocarpa é conhecido popularmente por jatobá-do-cerrado amplamente encontrado no domínio Cerrado. Ocorrendo nos estados do Piauí, Bahia, Goiás, Mato Grosso do Sul e São Paulo. O jatobá-do-cerrado habita formações de Cerrado nas variantes tipos cerradão, Cerrado aberto e Cerrado campo (Botelho et al., 2000).

A espécie $H$. stigonocarpa produz anualmente uma grande quantidade de frutos, apresentando formato de vagem, consumidos pela fauna local, de transição e pelas comunidades rurais. A casca do fruto apresenta coloração marrom castanho, com aroma marcante e rico em resina, no interior da vagem é encontrada uma polpa farinácea chamada de arilo com coloração verde amarelado, sabor doce e aroma característico. Internamente a polpa farinácea está disposta sementes com coloração roxa ao castanho escuro (Botelho et al., 2000).

A farinha do arilo pode ser utilizada na confeitaria, panificação e no preparo de cookies apresentando bom aceite da população que procura a cada dia por novos produtos naturais. Vários produtos de origem farinácea presentam características nutritivas ricas em sais minerais e com atividade antioxidante, auxiliando na manutenção da saúde e evitando doenças (Fasolin et al., 2007).

As farinhas são classificadas em farinha simples, produzidas a partir da moagem ou raladura, ou em farinha mista, obtida pela mistura de farinhas de diferentes espécies vegetais por métodos tecnológicos seguros garantindo a qualidade do produto conforme as normas estabelecidas pela Resolução - CNNPA no 12, de 1978 (Brasil, 2003). 0 aumento da produtividade por alimentos tem motivado constantemente o estudo de novas fontes naturais alternativas para conseguir maximizar a demanda de produção (Santana et al., 2017; Castilho et al., 2010).

0 estudo tecnológico envolvendo alimentos parte da necessidade para que possamos produzir mais com qualidade, e ao mesmo tempo preservando o meio ambiente. Os produtos de origem vegetal extrativista consome menor valor econômico gasto durante a produção e formulação de novos produtos (Santana et al., 2010; Seibel \& Beléia, 2009).

Conforme Santana et al. (2017), a aplicação dos produtos farináceos depende do seu desempenho como 
ingrediente funcional, bem como o seu comportamento tecnológico nos sistemas alimentícios, garantindo que os produtos tenham qualidade e que possam agregar a matériaprima nos mais diversos tipos de alimentos.

Os estudos bromatológicos dos constituintes químicos, tecnológicos funcionais e de características antioxidantes tornam-se essencial para uma avaliação segura de matérias-primas de origem vegetal utilizadas como alimentos.

Com isso, este estudo objetivou-se avaliar as características físico-químicas, tecnológicas, antioxidantes, conteúdos de fenólicos totais e carotenóides nas farinhas produzidas a partir do fruto de H. stigonocarpa.

\section{Material e métodos}

O experimento foi realizado no laboratório de Química Tecnológica do Instituto Federal Goiano, Campus Rio Verde/GO. Os frutos de H. stigonocarpa foram coletados em duas áreas de preservação localizados nos municípios de Montividiu e Rio Verde/GO. Uma exsicata foi herborizada e depositada no Herbário do IF Goiano com o seguinte registro: HRV 10039.

Os frutos foram lavados em água corrente e secos com folhas de papel absorvente. Em seguida, os frutos foram fraturados utilizando martelo para retirada do arilo e das sementes. As cascas e sementes foram fraturadas novamente em tamanhos com $1 \mathrm{~cm}$ de diâmetro. Em seguida foram moídas em moinho de facas tipo ciclone com peneira granulométrica interna 32 mesh. As farinhas produzidas foram armazenadas separadamente em embalagens plástica para alimentos à temperatura de $-8{ }^{\circ} \mathrm{C}$ até análises.

0 teor de umidade foi avaliado conforme IAL (2008) adaptado. Uma alíquota de $1 \mathrm{~g}$ de amostra foi pesada em cadinho e levada para estufa com circulação e renovação de ar forçada por 4 horas a $105{ }^{\circ} \mathrm{C}$. 0 resultado foi expresso em porcentagem.

$0 \mathrm{pH}$ foi determinado utilizando um potenciômetro digital conforme descrito por Bastos et al. (2016). Uma alíquota de $10 \mathrm{~g}$ de farinha foi acrescida com $60 \mathrm{~mL}$ de água destilada. A amostra foi homogeneizada por 1 minuto e deixada em descanso por 15 minutos. Em seguida realizou-se a leitura.

O conteúdo de cinzas foi determinado conforme Bastos et al. (2016) adaptado. Uma alíquota de $1 \mathrm{~g}$ de amostra foi submetida à calcinação em forno tipo mufla a $550{ }^{\circ} \mathrm{C}$ por 3 horas. 0 resultado foi expresso em porcentagem. 0 conteúdo de sólidos solúveis totais ( $\left.{ }^{\circ} \mathrm{Brix}\right)$ foi determinado de acordo com IAL (2008). 3 gotas do sobrenadante foi adicionado em um refratômetro portátil e o resultado expresso em ${ }^{\circ} \mathrm{Brix}$.

A fração lipídica foi determinada utilizando aparelho de Soxlhet. O hexano foi utilizado como solvente extrator. Cerca de $5 \mathrm{~g}$ de farinha foi pesada e transferida para um cartucho confeccionado em papel de filtro. 0 sistema ficou em refluxo por 6 horas. Logo após, o balão contendo a fração lipídica foi rotaevaporada com vácuo para retirada do solvente. 0 balão foi resfriado em dessecadora com sílica gel até temperatura de $25{ }^{\circ} \mathrm{C}$. Em seguida a massa do balão com amostra foi determinada. A porcentagem de extrativos lipídicos foi calculado pela diferença de peso como proposto por Mendonça et al. (2006) adaptado.

0 teor proteico total foi determinado através do método de Kjeldahl, conforme IAL (2008) adaptado. Uma amostra de $0,250 \mathrm{~g}$ foi pesada e submetida à reação catalítica. Utilizou-se o valor de 6,25 para o fator de conversão para proteína bruta. 0 resultado foi expresso em porcentagem.

A determinação da densidade aparente e real foi avaliada conforme descrito por Alcântara et al. (2012), e Frabetti (2017) adaptado. 0 teste foi realizado em proveta de $100 \mathrm{~mL}$ acrescida com $50 \mathrm{~mL}$ de farinha. Foram realizadas três batidas em uma superfície plana e regular com intervalos de 2 segundos. Em seguida foi realizada a leitura de compactação. Onde Da = Massa $(\mathrm{g}) /$ Volume aparente $(\mathrm{mL})$.

0 rendimento péctico foi determinado utilizando-se $5 \mathrm{~g}$ de farinha acrescida com $100 \mathrm{~mL}$ de uma solução aquosa de ácido cítrico $1 \mathrm{M} \mathrm{L}^{-1}$. A solução permaneceu em banho ultratermostático a $40^{\circ} \mathrm{C}$ por 60 minutos. Em seguida, a massa foi filtrada em pano nylon e o sobrenadante acrescido com 100 $\mathrm{mL}$ de álcool etílico 95\%. A pectina seca foi pesada determinando o rendimento de extração em porcentagem (Fertonani et al., 2006).

A molhabilidade foi avaliada conforme Duarte et al. (2017) adaptado. Uma alíquota de $1 \mathrm{~g}$ de farinha foi submetida à queda em $100 \mathrm{~mL}$ de água destilada a $25^{\circ} \mathrm{C}$. Ao mesmo tempo, foi cronometrado o tempo necessário para completa imersão. Os resultados foram expressos em minutos. A atividade da Água $\left(\mathrm{a}_{\mathrm{w}}\right.$ ) foi determinada conforme descrito Silva et al. (2013) adaptado. Para esta análise foi utilizado equipamento HygroPalm, com equalização em BOD a $25^{\circ} \mathrm{C}$.

Para a determinação da higroscopicidade, utilizaram-se frascos de vidro boro-silicato. Uma alíquota de 1 g de amostra após secagem em estufa a $105^{\circ} \mathrm{C}$ foi transferida para o frasco e levado para dessecadora contendo um ambiente de umidade relativa constante com 75\% UR. A amostra foi mantida por 7 dias e logo em seguida, o frasco foi pesado e a porcentagem de água absorvida foi calculada em relação ao peso da amostra seca, utilizando a seguinte expressão: $\mathrm{U}-[(\mathrm{Pu}-\mathrm{Ps}) / \mathrm{Ps}]$ x 100. Sendo $\mathrm{Pu}=$ peso, em g, da amostra úmida, e Ps = peso, em g, de amostra seca, conforme Alcarde et al. (1992) adaptado.

A porcentagem de carboidratos foi determinada conforme Santos et al. (2010). Através da diferença dos seguintes teores (umidade, cinzas, fração lipídica e proteínas) - 100. 0 resultado foi expresso em porcentagem. 0 valor calórico foi determinado através de uma bomba calorimétrica hiperbólica, sendo o resultado expresso em (kcal kg-1).

Para o equivalente de retinol (provitamina A), adotou-se a razão de conversão de $12 \mu \mathrm{g}$ de $\beta$-caroteno, que corresponde a 1 RAE (Retinol Activity Equivalent) conforme Ferreira et al. (2008).

Os minerais, potássio $(\mathrm{K})$, cálcio $(\mathrm{Ca})$, magnésio $(\mathrm{Mg})$, manganês $(\mathrm{Mn})$, zinco $(\mathrm{Zn})$, cobre $(\mathrm{Cu})$, enxofre $(\mathrm{S})$ e ferro $(\mathrm{Fe})$ foram determinados por espectrofotometria de absorção atômica. $\mathrm{O}$ fósforo (P) foi avaliado por fotômetro de chama conforme Sabino et al. (2017) adaptado. A análise colorimétrica foi realizada conforme Correia et al. (2009) adaptado. Os índices colorimétricos foram: para $\mathrm{L}^{*}$ (Luminosidade 0 (preto) - 100 (branco)), cromas a* (-a* verde/+a* vermelho), $\mathrm{b}^{*}$ (-b* azul/ $\mathrm{b}^{*}$ amarelo), $\mathrm{C}^{*}$ e ângulo hue $\mathrm{h}^{\circ}$.

O volume de inchamento (IV) foi determinado conforme Garcia et al. (2017). Amostra de $1 \mathrm{~g}$ foi adicionada em uma proveta graduada acrescida com água destilada em excesso. A suspensão foi agitada em Vortex por 15 minutos e deixada em repouso por 24 horas. 0 volume ocupado pela amostra na proveta ao final do tempo foi calculado pela diferença entre o volume inicial da amostra desidratada e o volume final da farinha intumescida conforme equação 1 :

$\mathrm{VI}=\mathrm{Vf}$ amostra $-\mathrm{Vi}$ amostra

Em que VI = volume de intumescimento; Vf = volume final $\mathrm{e}$ $\mathrm{Vi}=$ volume inicial.

0 índice de absorção em água e óleo (IAA/IAO) foi determinado conforme Santana et al. (2017). Uma suspensão com 0,5 g de farinha e $25 \mathrm{~mL}$ de água ou óleo foi homogeneizada em tubos cônicos. E em seguida centrifugado a $5000 \mathrm{rpm}$ por 25 minutos. O líquido sobrenadante foi escorrido e o material remanescente foi pesado. 0 líquido sobrenadante (água) foi utilizado para determinação da 
solubilidade em água (SA). Em placa de petri, o líquido foi evaporado em estufa a $105{ }^{\circ} \mathrm{C}$ por 4 horas. As seguintes equações 2 e 3 foram utilizadas para a determinação de (IAA/IAO e SA).

$$
\begin{aligned}
& \text { IAA } / \mathrm{IAO}=\text { água ou óleo absorvido pela amostra (g) } \\
& \text { Peso da amostra seca }(\mathrm{g}) \\
& \mathrm{SA}= \\
& \begin{aligned}
\text { resíduo de evaporação }(\mathrm{g}) \times 100 \\
\text { Peso da amostra }(\mathrm{g})
\end{aligned}
\end{aligned}
$$

A capacidade de formação de gel foi determinada conforme Santana et al. (2017) adaptado. Em tubos cônicos conteúdos farináceos em diferentes concentrações $(2,6,10$, $14,18,22$ e $26 \%$ ), foram acrescidos com $30 \mathrm{~mL}$ de água e submetidos ao aquecimento a $90^{\circ} \mathrm{C}$ por 30 minutos em banhomaria. Em seguida foram resfriados em geladeira a $8{ }^{\circ} \mathrm{C}$ por 2 horas. Os tubos foram invertidos e observou-se à formação de gel.

A atividade antioxidante seguiu conforme Menezes Filho et al. (2018) adaptado. Foram preparados extratos hidroetanólico 20\% (v/v) e hidrometanólico $50 \%$ (v/v) a partir das amostras de farinhas (casca, arilo e sementes) do fruto de $\mathrm{H}$. stigonocarpa. A atividade antioxidante foi determinada pelo método de captura do radical DPPH. Utilizou-se alíquota de $500 \mu \mathrm{L}$ do extrato hidrometanólico $50 \%$ acrescido com 1,5 mL de DPPH na concentração 0,06 mM. As amostras foram homogeneizadas manualmente por 1 minuto e armazenadas em local escuro por 60 minutos contados a partir do início da reação. A leitura foi realizada em espectrofotômetro UV-Vis no comprimento de ondas em 517 $\mathrm{nm}$. A porcentagem de captura de DPPH foi obtida conforme equação 4.

$\%$ DPPH $=($ Abscontrole - Absamostra $) \times 100 /$ Abscontrole

Os compostos fenólicos foram determinados conforme descrito por Rocha et al. (2013) adaptado. Onde 500 $\mu \mathrm{L}$ do extrato hidroetanólico $20 \%$, foi acrescido com $8 \mathrm{~mL}$ de água destilada e $500 \mu \mathrm{L}$ de uma solução Folin-Ciocalteau na concentração (1:10) em água destilada (v/v). Em seguida as amostras foram homogeneizadas por 5 minutos $\mathrm{e}$ acrescentou-se $1 \mathrm{~mL}$ de uma solução aquosa de carbonato de sódio anidro 7,5\% (m/v). As amostras foram armazenadas em local escuro por 60 minutos e a leitura foi realizada em espectrofotômetro UV-Vis no comprimento de ondas em 720 nm. Uma curva-padrão de ácido gálico foi construída nas concentrações mg L-1 em equivalente de ácido gálico.

A determinação dos flavonoides e antocianinas foi realizada conforme Rocha et al. (2013) adaptado. Inicialmente foram preparados extratos com 0,5 g para cada amostra em uma solução extratora composta por etanol $99 \%$ e ácido clorídrico 1,5 N na proporção (85:15). As amostras foram homogeneizadas por 5 minutos e em seguida transferidas sem filtração para balões volumétricos de $25 \mathrm{~mL}$ acrescidos até menisco com a solução extratora. As amostras foram armazenadas em refrigerador a $-8^{\circ} \mathrm{C}$ por 12 horas. Em seguida, foram filtradas em papel de filtro qualitativo em local escuro. A leitura foi realizada em espectrofotômetro UV-Vis no comprimento de ondas em $535 \mathrm{~nm}$.

Para o cálculo do teor de antocianinas seguiu-se conforme a equação: (Absamostra x fator de diluição/98,2) dividindo-se pela massa seca da amostra $(0,5 \mathrm{~g})$ pelo volume da solução (25 mL). Os resultados foram expressos em mg 100 g-1. 0 mesmo procedimento foi realizado para flavonoides sendo a leitura espectrofotométrica em $374 \mathrm{~nm}$.

Os teores de $\beta$-caroteno e licopeno foram determinados conforme Nagata \& Yamashita (1992) adaptado. Extratos aceto-hexânicos na proporção (4:6) (v/v) foram preparados a partir de $5 \mathrm{~g}$ de amostra farinácea. A solução foi armazenada em refrigerador a $-8^{\circ} \mathrm{C}$ por 12 horas. Em seguida os extratos foram filtrados as leituras realizadas em espectrofotômetro UV-Vis nos comprimentos de ondas 453; 505; 645 e $662 \mathrm{~nm}$. As equações 5 e 6 foram utilizadas para os cálculos de determinação do $\beta$-caroteno e licopeno. Em seguida, os resultados foram multiplicados por 1.000 e expressos em $\mu \mathrm{g} 100 \mathrm{~g}-1$ de amostra seca.

$\beta$-caroteno $=(0,216 \times \mathrm{A} 663)-(1,22 \times \mathrm{A} 645)-(0,304 \times \mathrm{A} 505)+$ $(0,452 \times \mathrm{A} 453)$

Licopeno $=(-0,0458 \times \mathrm{A663})+(0,204 \times \mathrm{A} 645)+(0,372 \times \mathrm{A} 505)$ - $(0,0806 \times \mathrm{A} 453)$

Todas as análises foram realizadas em triplicata e os resultados avaliados por análise de variância (ANOVA) e a diferença estatística pelo teste de Tukey a $(\mathrm{p}<0,05)$. Para a análise estatística foi utilizado Software Past3 (PALeontological Statistics).

\section{Resultados e discussão}

Na Tabela 1 são apresentados os resultados da composição físico-química das farinhas da casca, arilo e

\begin{tabular}{|c|c|c|c|}
\hline Análises & $\begin{array}{l}\text { Casca } \\
\text { Fruto }\end{array}$ & $\begin{array}{l}\text { Arilo } \\
\text { Fruto }\end{array}$ & Semente \\
\hline Umidade (\%) & $\begin{array}{c}5,37 \pm \\
0,16^{c}\end{array}$ & $\begin{array}{c}9,94 \pm \\
0,07^{\mathrm{a}}\end{array}$ & $\begin{array}{c}8,49 \pm \\
0,15^{b}\end{array}$ \\
\hline $\mathrm{pH}$ & $\begin{array}{c}5,16 \pm \\
0,04^{c}\end{array}$ & $\begin{array}{c}5,75 \pm \\
0,02^{\mathrm{b}}\end{array}$ & $\begin{array}{c}6,44 \pm \\
0,04^{\mathrm{a}}\end{array}$ \\
\hline Cinzas $(\%)$ & $\begin{array}{r}1,28 \pm \\
0,02^{\mathrm{c}}\end{array}$ & $\begin{array}{c}4,57 \\
\pm 0,16^{\mathrm{a}}\end{array}$ & $\begin{array}{c}1,84 \pm \\
0,06^{b}\end{array}$ \\
\hline${ }^{\circ} \operatorname{Brix}(\%)$ & $\begin{array}{c}2,77 \pm \\
0,11^{\mathrm{b}}\end{array}$ & $\begin{array}{c}5,90 \pm \\
0,10^{\mathrm{a}}\end{array}$ & $\begin{array}{c}1,50 \pm \\
0,00^{c}\end{array}$ \\
\hline Lipídeos (\%) & $\begin{array}{c}4,03 \pm \\
0,19 a\end{array}$ & $\begin{array}{r}1,57 \pm \\
0,08^{\mathrm{c}}\end{array}$ & $\begin{array}{c}3,49 \pm \\
0,11^{\mathrm{b}}\end{array}$ \\
\hline Proteínas (\%) & $\begin{array}{c}4,14 \pm \\
0,01^{\mathrm{c}}\end{array}$ & $\begin{array}{c}9,85 \pm \\
0,74^{\mathrm{b}}\end{array}$ & $\begin{array}{c}10,25 \pm \\
0,71^{\mathrm{a}}\end{array}$ \\
\hline Densidade aparente $\left(\mathrm{g} \mathrm{cm}^{3}\right)$ & $\begin{array}{c}0,60 \pm \\
0,02^{\mathrm{b}}\end{array}$ & $\begin{array}{r}0,37 \pm \\
0,00^{\mathrm{c}}\end{array}$ & $\begin{array}{c}0,72 \pm \\
0,02^{\mathrm{a}}\end{array}$ \\
\hline Densidade real $\left(\mathrm{g} \mathrm{cm}^{3}\right)$ & $\begin{array}{c}0,55 \pm \\
0,02^{b}\end{array}$ & $\begin{array}{c}0,40 \pm \\
0,00^{c}\end{array}$ & $\begin{array}{c}0,71 \pm \\
0,00^{\mathrm{a}}\end{array}$ \\
\hline Pectina $(\%)$ & nd* & $\begin{array}{c}31,39 \pm \\
0,68^{b^{* *}}\end{array}$ & $\begin{array}{c}37,73 \pm \\
0,12^{a^{* *}}\end{array}$ \\
\hline Molhabilidade (min.) & $\begin{array}{c}51,24 \\
\pm 1,00^{\mathrm{a}}\end{array}$ & $\begin{array}{c}29,76 \pm \\
1,51^{b}\end{array}$ & $\begin{array}{c}12,23 \pm \\
0,19 \mathrm{c}\end{array}$ \\
\hline Atividade da água $\left(\mathrm{a}_{\mathrm{w}}\right)$ & $\begin{array}{c}0,53 \pm \\
0,00^{\mathrm{b}}\end{array}$ & $\begin{array}{c}0,50 \pm \\
0,00^{\mathrm{c}}\end{array}$ & $\begin{array}{c}0,60 \pm \\
0,00^{\mathrm{a}}\end{array}$ \\
\hline Higroscopicidade (\%) & $\begin{array}{c}9,66 \pm \\
0,22^{c}\end{array}$ & $\begin{array}{c}16,68 \pm \\
0,20^{\mathrm{a}}\end{array}$ & $\begin{array}{c}14,85 \pm \\
0,06^{b}\end{array}$ \\
\hline Carboidratos & $\begin{array}{c}62,73 \\
\pm 1,16^{c}\end{array}$ & $\begin{array}{c}74,13 \pm \\
0,86^{b}\end{array}$ & $\begin{array}{c}75,99 \pm \\
0,44^{\mathrm{a}}\end{array}$ \\
\hline Valor calórico (kcal kg-1) & $\begin{array}{l}503,93 \\
\pm 0,72^{\mathrm{a}}\end{array}$ & $\begin{array}{c}350,37 \pm \\
0,68^{c}\end{array}$ & $\begin{array}{c}376,16 \pm \\
0,55^{b}\end{array}$ \\
\hline Vitamina A (RAE $100 \mathrm{~g}^{-1}$ ) & $\begin{array}{l}3,54 \pm \\
0,01^{b^{* *}}\end{array}$ & $\begin{array}{l}5,73 \pm \\
0,10^{a^{* *}}\end{array}$ & nd* \\
\hline
\end{tabular}
semente do fruto de H. stigonocarpa.

Tabela 1. Parâmetros físico-químicos de farinhas da casca, arilo e semente do fruto de Hymenaea stigonocarpa.

${ }^{*}$ nd = não detectado. ${ }^{* *}$ Avaliado pelo teste de $t$ Student. RAE $=$ Retinol activity Equivalent, onde $1 \mathrm{RAE}=1 \mu \mathrm{g}$ de retinol $=12 \mu \mathrm{g} \beta$-caroteno. Médias seguidas da mesma letra na linha não diferem entre si pelo teste de Tukey a $(\mathrm{p}<0,05)$.

A farinha da casca apresentou o menor teor de umidade de 5,37\%. Os maiores valores de umidade foram observados nas farinhas da semente e arilo com 8,49 e 9,94\%. As farinhas da semente e arilo devido ao maior conteúdo de umidade necessitam passar por processos adicionais de termoconversão (maior tempo e maior temperatura de tratamento) e optar pela embalagem em sistema a vácuo. Com isso garantindo a integridade do produto. 0 teor de umidade é um dos parâmetros avaliados para produtos farináceos, 
apresentando um teor máximo de umidade menor ou igual a 15\% (Brasil, 2005).

A norma vigente no Brasil cita unicamente a farinha de trigo nas especificações para produtos farináceos, não sendo aplicados a produtos alternativos. Em comparação com a normativa para umidade do produto farináceo, as farinhas do fruto de $H$. stigonocarpa neste estudo, atendem a legislação brasileira. Outro fator importante sobre o teor de umidade é sobre a sua maior durabilidade, onde quanto menor a umidade, menor o crescimento microbiano. Valores superiores aos encontrados neste estudo foram descritos por Costa et al. (2017) para farinha do mesocarpo do pequi, os autores encontraram teor de umidade igual a 15,58\%. Em outro estudo Queiroz et al. (2015) encontraram para as farinhas da casca e semente de lichia teor de umidade de 6,10 e $8,7 \%$, similar ao observado neste estudo.

$\mathrm{O}$ pH é um outro importante fator na análise de um produto farináceo visto que, resultados acima de 4,0 podem favorecer o desenvolvimento de fungos deterioradores e diminuir o tempo de vida útil do produto no mercado (Costa et al., 2017; Souza et al., 2008). As farinhas do fruto de $H$. stigonocarpa apresentaram pHs iguais a 5,16; 5,75 e 6,44. Com estes resultados obtidos, é sugerido que as farinhas sejam embaladas a vácuo evitando a presença de vapor de água em contato com a farinha garantindo um tempo maior para a vida útil do produto. Quando comparadas a outros estudos farináceos, podemos observar que Costa et al. (2017) obtiveram pH 4,16 para farinha do mesocarpo do fruto do pequizeiro. Já no estudo realizado por Albuquerque et al. (2016) com pH 3,17 para a farinha dos resíduos de seriguela. Estes autores obtiveram resultados de $\mathrm{pH}$ inferiores aos obtidos neste estudo para as farinhas do fruto de $H$. stigonocarpa.

0 teor de minerais em cinzas para as farinhas do fruto de $H$. stigonocarpa apresentaram resultados iguais a 1,$28 ; 4,57$ e $1,84 \%$ para casca, arilo e semente respectivamente. 0 teor de cinzas para a farinha do arilo apresentou expressivo teor sugerindo ser uma farinha rica em minerais, podendo ser emprega na produção de barras de cerais ricas em nutrientes.

Estudo realizado por Silva et al. (2001) avaliando as farinhas dos frutos do jatobá-do-cerrado e de jatobá-da-mata, obtiveram teores de cinzas iguais a 4,60 e 5,48\%, próximo ao obtido neste estudo para farinha do arilo do fruto de $H$. stigonocarpa. Já Rodrigues \& Silva (2017) encontraram conteúdo de cinzas igual a 5,85\% para farinha do fruto do maracujazeiro.

Os sólidos solúveis totais expressos em ${ }^{\circ} \mathrm{Brix}$ apresentaram resultados de 2,77; 5,90 e 1,50 para as farinhas da casca, arilo e semente do fruto de $H$. stigonocarpa. $0{ }^{\circ} \mathrm{Brix}$ na farinha do arilo apresentou expressivo teor de açúcares solúveis em suspensão. Mesmo apresentando um baixo quantitativo de açúcares livres, as farinhas ainda apresentam ser ótimas opções para uso alimentar. Outros estudos avaliando diferentes farinhas de origem vegetal apresentaram teores superiores aos obtidos nas farinhas do fruto de $H$. stigonocarpa. Queiroz et al. (2015) encontraram para as farinhas da casca e semente de lichia quantitativos de açúcares livres iguais a 20,00 e $15,00{ }^{\circ}$ Brix respectivamente. Já no estudo realizado por Clemente et al. (2012) os pesquisadores obtiveram resultado de $38,5^{\circ}$ Brix para a farinha do bagaço de laranja.

A fração lipídica obtida foi igual a 4,03; 1,57 e 3,49\% para casca, arilo e semente de $H$. stigonocarpa respectivamente. A casca do fruto apresentou quantitativo lipídico superior ao obtido pela semente, demonstrando ser uma ótima opção para compostos lipídicos alternativos. Hubinger et al. (2009) encontraram resultado superior aos verificados neste estudo para o pó do fruto do faveiro, os autores obtiveram resultado igual a $31,9 \%$ de extrativos. As frações lipídicas variam entre as farinhas nos mais diversos frutos.

0 teor proteico foi significativo para as farinhas avaliadas neste estudo. Os teores obtidos foram de 4,14; 9,85 e $10,25 \%$ para casca, arilo e semente respectivamente. Observa-se que as farinhas do arilo e sementes apresentam importantes fontes proteicas. Com estes resultados sugere-se que estas farinhas podem ser empregadas em alimentos que necessitam contem altos teores proteicos. A farinha do arilo neste estudo apresentou resultado superior ao obtido por Silva et al. (2001) avaliando a mesma espécie H. stigonocarpa. Rodrigues \& Silva (2017) obtiveram resultado igual a 4,51\% para farinha do fruto do maracujá, também sendo uma farinha rica em compostos proteicos.

A densidade aparente apresentou resultados de 0,60; 0,37 e 0,72 g cm3 respectivamente para as farinhas da casca, arilo e semente. Ambas as farinhas da casca e semente, apresentam maior densidade, seno consideradas farinhas pesadas. Já Hubinger et al. (2009) encontraram para o pó do fruto do faveiro resultado igual a $0,56 \mathrm{~g} \mathrm{~cm}^{3}$.

Para os compostos pécticos, os resultados obtidos neste estudo são inéditos para as farinhas do arilo e semente onde obtiveram teor de extração de 31,39 e 37,73\% respectivamente. Os resultados deste estudo são superiores quando comparados ao observados por Rodrigues \& Silva (2017) onde obtiveram teor de extração de pectina igual a 21,06 e $26,45 \%$ utilizando o método convencional (extração ácida) e por ultrassom na farinha do fruto do maracujazeiro. Os extrativos pécticos obtidos para as farinhas do arilo e semente apresentam importante fonte de pectina podendo ser utilizada na indústria de alimentos como espessante em bebidas e como aditivo em formulações alimentícias.

A molhabilidade apresentou diferença significativa entre as três amostras de farinhas (casca, arilo e semente) do fruto de $H$. stigonocarpa. 0 maior tempo para que $90 \%$ do particulado farináceo fossem submersos, foi observado na farinha da casca do com tempo igual a 51,24 min. Esse tempo superior envolve possíveis fatores como teor de lipídeos e a presença de resinas que estruturalmente possuem características hidrofóbicas. As farinhas do arilo e da semente obtiveram tempo respectivo de 29,76 e 12,23 min. Estes resultados apresentam para ambas as farinhas bons tempos de molhabilidade para a produção de alimentos cuja mistura é realizada por meio de líquidos.

De acordo com Shaw (1992), a molhabilidade é definida pelo deslocamento de um líquido por outro em uma superfície. Em particulados alimentícios, a capacidade de um sólido absorver líquido pela acessão capilar ou por um sólido conhecido para que seja totalmente molhado.

As atividades de água apresentaram respectivamente resultados de 0,$53 ; 0,50$ e 0,60 aw para as farinhas da casca, arilo e semente respectivamente. Estes resultados são considerados bons para produtos farináceos. Onde quanto menor a atividade de água, menor a ação enzimática e menor ação por degradação exercida por microrganismos deterioradores.

As farinhas do arilo e da semente apresentaram maior teor de absorção de água pelo ambiente igual a 16,68 e $14,85 \%$ e em menor quantidade para a farinha da casca do fruto $9,66 \%$. A higroscopicidade é representada pela porcentagem de água absorvida pela farinha em um determinado tempo com uma atmosfera de $75 \%$ de umidade relativa. Estes resultados demonstraram que ambas as farinhas do arilo e semente necessitam de processos especiais para serem embaladas, como por exemplo, a embalagem a vácuo.

Os carboidratos obtidos por diferença neste estudo foram iguais a 62,73; 74,13 e 75,99\% para as farinhas da casca, arilo e semente respectivamente. Os teores quantitativos obtidos neste estudo demonstraram que as farinhas são fontes 
importantes de energia podendo ser empregadas em barras de cereais, in natura ou tostadas. De acordo com Júnior \& Carvalho (2018) os vegetais apresentam importante fonte de carboidratos de fácil disposição.

Os valores calóricos apresentaram resultados iguais a 503,$93 ; 350,37$ e $376,16 \mathrm{kcal} \mathrm{kg-1}^{-1}$ para as farinhas da casca, arilo e semente respectivamente. A farinha da casca do fruto apresentou o maior valor calórico esta farinha pode ser empregada na produção de biscoitos tipo cookie. Os resultados deste estudo estão próximos aos obtidos por Queiroz et al. (2015) para as farinhas da casca e semente de lichias de 343,04 e $397,66 \mathrm{kcal} \mathrm{kg}^{-1}$.

Os teores de vitamina A em equivalente de retinol apresentaram resultados de 3,54 e 5,73 RAE $100 \mathrm{~g}^{-1}$ para as farinhas da casca e arilo respectivamente. Os resultados apresentaram importantes quantitativos de vitamina A. Esta vitamina é utilizada na produção de sucos, alimentos e em fórmulas farmacêuticas para uso interno e em loções tópicas enriquecidas com vitaminas. Hiane et al. (2003) estudando a farinha do bacuri obtiveram expressivo quantitativo de vitamina A igual a 454 RAE $100 \mathrm{~g}^{-1}$.

$\mathrm{Na}$ Tabela 2 podem-se verificar os resultados da composição mineral para as farinhas da casca, arilo e semente do fruto de H. stigonocarpa.

Tabela 2. Composição mineral das farinhas da casca, arilo e semente do fruto do jatobá-do-cerrado (Hymenaea stigonocarpa).

\begin{tabular}{lccc}
\hline Minerais & Casca & Arilo & Semente \\
\cline { 2 - 4 } Fósforo (P) & $0,90 \pm 0,00^{\mathrm{b}}$ & $1,67 \pm 0,05^{\mathrm{a}}$ & $2,1 \pm 0,05^{\mathrm{a}}$ \\
Potássio (K) & $1,83 \pm 0,06^{\mathrm{c}}$ & $14,47 \pm 0,05^{\mathrm{a}}$ & $4,0 \pm 0,05^{\mathrm{b}}$ \\
Cálcio (Ca) & $9,37 \pm 0,06^{\mathrm{a}}$ & $8,50 \pm 0,00^{\mathrm{b}}$ & $1,3 \pm 0,05^{\mathrm{c}}$ \\
Magnésio (Mg) & $31,90 \pm 0,10^{\mathrm{a}}$ & $31,73 \pm 0,09^{\mathrm{a}}$ & $1,0 \pm 0,00^{\mathrm{b}}$ \\
Ferro (Fe) & $44,40 \pm 0,10^{\mathrm{a}}$ & $\mathrm{nd}^{*}$ & $4,5 \pm 0,00^{\mathrm{b}}$ \\
Manganês & $127,43 \pm$ & $127,00 \pm$ & $44,2 \pm 0,05^{\mathrm{c}}$ \\
(Mn) & $0,11^{\mathrm{a}}$ & $0,00^{\mathrm{b}}$ & \\
Cobre (Cu) & $23,07 \pm 0,06^{\mathrm{a}}$ & $0,53 \pm 0,00^{\mathrm{c}}$ & $7,4 \pm 0,00^{\mathrm{b}}$ \\
Zinco (Zn) & - & - & $11,4 \pm 0,00$ \\
Enxofre (S) & - & - & $0,6 \pm 0,00$
\end{tabular}

Macronutrientes expressos em (g kg-1) e Micronutrientes expressos em $\left(\mathrm{mg} \mathrm{kg}^{-1}\right)$. *nd = não detectado. ( - ) Não avaliado. Médias seguidas de mesma letra na linha, para cada parâmetro avaliado, não diferem entre si pelo teste de Tukey a $(\mathrm{p}<0,05)$.

Os macronutrientes apresentaram neste estudo teores variáveis, em especial para o teor de $\mathrm{P}$ encontrado na farinha da semente de 2,1 g kg-1; o teor de $\mathrm{K}$ apresentou maior quantitativo na farinha do arilo com 14,47 $\mathrm{g} \mathrm{kg}^{-1}$; já para o teor de Ca de 9,37 $\mathrm{g} \mathrm{kg}^{-1}$ para farinha da casca do fruto. Os teores de Mg não apresentaram diferença significativa para as farinhas da casca e arilo com 31,90 e 31,73 $\mathrm{g} \mathrm{kg}^{-1}$ respectivamente. 0 elemento $\mathrm{S}$ foi apenas detectado na farinha da semente apresentando resultado de $0,6 \mathrm{~g} \mathrm{~kg}^{-1}$ como observado na (Tabela 2).

Para os micronutrientes o $\mathrm{Fe}$ apresentou elevado teor na farinha da caca com 44,40 $\mathrm{mg} \mathrm{kg}^{-1}$. Os teores de $\mathrm{Mn}$ diferiram significativamente entre as três farinhas apresentando os maiores quantitativos de 127,43 e 127,00 mg $\mathrm{kg}^{-1}$ na farinha da casca e arilo respectivamente. Os teores de $\mathrm{Cu}$ também apresentaram diferença significativa entre as farinhas em especial, para a farinha da casca com 23,07 mg kg1. 0 elemento $\mathrm{Zn}$ foi apenas detectado na farinha da semente com 11,4 $\mathrm{mg} \mathrm{kg}^{-1}$ conforme (Tabela 2).

As farinhas da casca, arilo e sementes do $\mathrm{H}$. stigonocarpa apresentaram importantes teores minerais. Esta característica química é importante para a produção de alimentos ricos em fontes minerais, podendo ser empregados principalmente em países com déficit nutricional entre a população de baixa renda, sendo uma excelente opção para suplementação mineral deficiente.

Os parâmetros colorimétricos para as farinhas da casca, arilo e semente do fruto de H. stigonocarpa podem ser observado na Tabela 3.

Tabela 3. Parâmetros colorimétricos para as farinhas da casca, arilo e semente do fruto de Hymenaea stigonocarpa.

\begin{tabular}{|c|c|c|c|c|c|}
\hline \multirow[t]{2}{*}{ Amostra } & \multicolumn{3}{|c|}{ Cor } & \multirow[t]{2}{*}{$C^{*}$} & \multirow[t]{2}{*}{$h^{\circ}$} \\
\hline & $\mathbf{L}^{*}$ & $\mathbf{a}^{*}$ & $\mathbf{b}^{*}$ & & \\
\hline Casca & $\begin{array}{c}71,59 \pm 0 \\
00^{\mathrm{b}}\end{array}$ & $\begin{array}{c}5,19 \pm 0 \\
, 00^{\mathrm{a}}\end{array}$ & $\begin{array}{c}16,63 \pm 0 \\
01^{\mathrm{b}}\end{array}$ & $\begin{array}{c}17,42 \\
\pm 0,01^{b}\end{array}$ & $\begin{array}{c}72,68 \pm 0 \\
04^{\mathrm{c}}\end{array}$ \\
\hline Arilo & $\begin{array}{c}72,97 \pm 0 \\
02^{\mathrm{a}}\end{array}$ & $\begin{array}{c}0,90 \pm 0 \\
, 01^{\mathrm{c}}\end{array}$ & $\begin{array}{c}32,18 \pm 0 \\
01^{\mathrm{a}}\end{array}$ & $\begin{array}{c}32,19 \\
\pm 0,01^{\text {a }}\end{array}$ & $\begin{array}{c}88,40 \pm 0 \\
00^{\mathrm{a}}\end{array}$ \\
\hline Semente & $\begin{array}{c}65,06 \pm 0 \\
00^{c} \\
\end{array}$ & $\begin{array}{c}2,77 \pm 0 \\
, 01^{\mathrm{b}} \\
\end{array}$ & $\begin{array}{c}12,02 \pm 0 \\
02^{\mathrm{c}}\end{array}$ & $\begin{array}{r}12,46 \\
\pm 0,17 \mathrm{c} \\
\end{array}$ & $\begin{array}{c}77,16 \pm 0, \\
23^{\mathrm{b}}\end{array}$ \\
\hline
\end{tabular}

Médias seguidas de mesma letra na mesma coluna, para cada parâmetro avaliado, não diferem entre si pelo teste de Tukey a $(\mathrm{p}<$ $0,05)$.

Na coordenada $L^{*}$ a farinha do arilo apresentou maior luminosidade igual a 72,97 e menor $L^{*}$ para a farinha da semente de 65,06 . Isto já era esperado, devido à coloração externa do tegumento da semente que apresenta coloração marrom castanho. Para os resultados de cromaticidade em $\mathrm{a}^{*}$ a maior tendência à cor vermelha foi verificada para a farinha da casca com a* de 5,19 e para croma b* com tendência a cor amarela de 32,19 observada na farinha do arilo. As farinhas do fruto do jatobá neste estudo apresentaram boa luminosidade e bons tons de cor para croma $\mathrm{a}^{*}$ e $\mathrm{b}^{*}$, em especial para a farinha do arilo que apresentou maior tom para o amarelo. Farinhas com tonalidades mais claras entre o amarelo ao branco são fatores de importância para o consumidor exigente, que busca por farinhas com maior brilho e cores claras (Cereda \& Vilpoux, 2010).

Outros importantes fatores na avaliação colorimétrica de um produto são saturação ( $\left.C^{*}\right)$ que representa a pureza da cor, e a tonalidade $\left(\mathrm{h}^{\circ}\right)$ que caracteriza a qualidade da cor. A farinha do arilo apresentou melhor saturação de cor com $C^{*}$ de 32,19 , e tonalidade $h^{\circ}$ com 88,40. Comparado estes resultados entre os obtidos por Costa et al. (2017), onde avaliaram a colorimetria da farinha do mesocarpo do pequi, os pesquisadores obtiveram $L^{*}$ de 73,70 , cromas a* de 6,10 e b* de 45,43, já para C* igual a 49,59 e h ${ }^{\circ}$ de 42,40 , se tratando de uma farinha com maior brilho, tons de vermelho e amarelo $\left(\mathrm{a}^{*} / \mathrm{b}^{*}\right)$. As farinhas do fruto de $H$. stigonocarpa apresentaram boas condições colorimétricas podendo ser aplicadas a testes sensoriais futuros para avaliação da aceitabilidade por consumidores.

Os volumes de inchamento para as farinhas foram de 0,2; 1,97 e 6,17 m3 kg-1 para casca, arilo e semente respectivamente do fruto de $H$. stigonocarpa. As farinhas do arilo e semente demonstram neste estudo tratar-se de farinhas com capacidade de absorver maior quantidade de líquidos podendo ser empregadas na produção de alimentos pastosos. Estudo realizado por Garcia et al. (2017), avaliando diferentes volumes de inchamento para farinhas do mamão (casca e semente), melão (casca e semente) e goiaba (casca e semente) encontraram resultados de 3,$93 ; 3,0 ; 8,67 ; 4,20 ; 1,60$ e $1,20 \mathrm{~m}^{3}$ $\mathrm{kg}^{-1}$ respectivamente, próximos aos observados neste estudo para as farinhas do fruto de H. stigonocarpa.

De acordo com Garcia et al. (2017), o intumescimento é definido como o volume ocupado em uma proveta (farinha)e a sua capacidade de reter líquido em certa massa (g) conhecida. 
Tabela 4. Parâmetros funcionais tecnológicos, atividade antioxidante, fenólicos totais, antocianinas, flavonoides, $\beta$-caroteno e licopeno determinados nas farinhas da casca, arilo e semente do fruto do Hymenaea stigonocarpa

\begin{tabular}{|c|c|c|c|}
\hline Parâmetros & $\begin{array}{l}\text { Casca } \\
\text { Fruto } \\
\end{array}$ & $\begin{array}{l}\text { Arilo } \\
\text { Fruto }\end{array}$ & $\begin{array}{c}\text { Semente } \\
\text { Fruto }\end{array}$ \\
\hline VI $\left(\mathrm{m}^{3} \mathrm{~kg}^{-1}\right)$ & $\begin{array}{l}0,2 \pm \\
0,10^{\mathrm{c}}\end{array}$ & $\begin{array}{c}1,97 \pm \\
0,15^{b}\end{array}$ & $\begin{array}{c}6,17 \pm \\
0,55^{\mathrm{a}}\end{array}$ \\
\hline IAA (\%) & $\begin{array}{c}2,95 \pm \\
0,47 \mathrm{c}\end{array}$ & $\begin{array}{c}4,33 \pm \\
0,15^{b}\end{array}$ & $\begin{array}{c}5,70 \pm \\
0,10^{\mathrm{a}}\end{array}$ \\
\hline IAO (\%) & $\begin{array}{c}2,49 \pm \\
0,34^{\mathrm{b}}\end{array}$ & $\begin{array}{c}2,64 \pm \\
0,12^{\mathrm{a}}\end{array}$ & $\begin{array}{r}2,09 \pm \\
0,07 \mathrm{c}\end{array}$ \\
\hline AS (\%) & $\begin{array}{c}8,33 \pm \\
0,29^{b}\end{array}$ & $\begin{array}{c}42,52^{ \pm} \\
1,51^{\mathrm{a}}\end{array}$ & $\begin{array}{c}7,19 \pm \\
0,33^{c}\end{array}$ \\
\hline DPPH & $\begin{array}{c}87,13 \pm \\
0,48^{\mathrm{b}}\end{array}$ & $\begin{array}{c}79,31 \pm \\
0,99 \mathrm{c}\end{array}$ & $\begin{array}{c}89,27 \pm \\
0,30^{a}\end{array}$ \\
\hline Fenólicos $\left(\mu \mathrm{g}\right.$ EAG $\left.100 \mathrm{~g}^{-1}\right)$ & $\begin{array}{c}14,52 \pm \\
2,10^{\mathrm{a}}\end{array}$ & $\begin{array}{c}3,55 \pm \\
0,15^{\mathrm{c}}\end{array}$ & $\begin{array}{c}9,13 \pm \\
0,04^{b}\end{array}$ \\
\hline Antocianinas (mg $100 \mathrm{~g}^{-1}$ ) & $\begin{array}{c}0,03 \pm \\
0,00^{\mathrm{b}}\end{array}$ & $\begin{array}{c}0,08 \pm \\
0,00^{\mathrm{a}}\end{array}$ & $\begin{array}{c}0,01 \pm \\
0,00^{c}\end{array}$ \\
\hline Flavonoides (mg $\left.100 \mathrm{~g}^{-1}\right)$ & $\begin{array}{c}0,21 \pm \\
0,00^{\mathrm{c}}\end{array}$ & $\begin{array}{c}0,23 \pm \\
0,00^{\mathrm{b}}\end{array}$ & $\begin{array}{c}0,27 \pm \\
0,00^{\mathrm{a}}\end{array}$ \\
\hline$\beta$-caroteno $\left(\mu \mathrm{g} 100 \mathrm{~g}^{-1}\right)$ & $\begin{array}{c}42,53 \pm \\
0,18^{b^{*}}\end{array}$ & $\begin{array}{c}68,71 \pm \\
1,19 a^{*}\end{array}$ & $\mathrm{nd}^{* *}$ \\
\hline Licopeno $\left(\mu \mathrm{g} 100 \mathrm{~g}^{-1}\right)$ & $\begin{array}{c}31,00 \pm \\
0,02^{\mathrm{c}}\end{array}$ & $\begin{array}{c}53,32 \pm \\
0,18^{\mathrm{b}} \\
\end{array}$ & $\begin{array}{c}130,29 \pm \\
0,86^{\mathrm{a}} \\
\end{array}$ \\
\hline
\end{tabular}

VI = Volume de inchamento, IAA = Índice de absorção de água, IAO = Índice de absorção de óleo e AS = Solubilidade em água. Médias seguidas de mesma letra na linha não diferem entre si pelo teste de Tukey a $(\mathrm{p}<0,05) .{ }^{*}$ Avaliado pelo teste de $t$ Student. $\mathrm{nd}^{* *}=$ não detectado.

0 índice de absorção de água também apresentou diferença significativa entre as três amostras farinhas para este estudo com o fruto de $H$. stigonocarpa. A farinha da semente apresentou maior capacidade de absorção de água com $6,17 \%$ seguido da farinha do arilo com $4,33 \%$ e da farinha da casca com 2,95\%. Para absorção de óleo a farinha do arilo apresentou o melhor resultado com 2,64\% seguido da farinha da casca de $2,49 \%$ e da semente com $2,09 \%$. Os resultados obtidos neste estudo poderão ser empregados no desenvolvimento de novos produtos alimentícios, visto que a capacidade de absorção de água e óleo são propriedades importantes na produção de alimentos em sistemas nutracêuticos aquosos (Silva-Sanchez et al., 2004).

Em estudo, Costa et al. (2017) obtiveram resultados para farinha do mesocarpo do pequi com 450,00\% para absorção de água e de 173,33\% para absorção de óleo. Já Souza et al. (2008) encontraram para a farinha casca do fruto do maracujazeiro capacidade de absorção de água de 6,02\% e de 1,17\% para óleo.

Os melhores valores de solubilidade em água foram observados para farinha do arilo com $42,52 \%$, seguido das farinhas da casca e semente com 8,33 e 7,19\% respectivamente. Santana et al. (2017) encontraram para as farinhas de linhaça dourada 15,33\%, feijão branco $14,00 \%$, linhaça marrom $14,00 \%$, uva $13,00 \%$ e maracujá $10,00 \%$. De acordo com Leonel et al. (2009), os autores discutem sobre os altos resultados de solubilidade em água para a produção de alimentos que requerem baixas temperaturas como molhos e sopas. A farinha do arilo demonstrou ser uma ótima opção para o preparo destes tipos de alimentos.

A atividade antioxidante determinada através da redução do radical livre DPPH, apresentaram diferenças significativas para os três extratos farináceos do fruto $d e H$. stigonocarpa avaliados neste estudo. A maior redução de DPPH foi observada no extrato farináceo da semente com $89,27 \%$ seguido dos extratos farináceos da casca e arilo com 87,13 e $79,31 \%$ respectivamente. Estes resultados demonstraram que as farinhas do fruto de $H$. stigonocarpa apresentaram importante ação antioxidante, podendo prevenir a ação de radicais livres como o oxigênio singleto.
Os compostos fenólicos totais apresentaram resultados iguais a 14,$52 ; 3,55$ e $9,13 \mu \mathrm{g} 100 \mathrm{~g}^{-1}$ para as farinhas da casca, arilo e sementes de $H$. stigonocarpa respectivamente. Os compostos fenólicos apresentam como um dos grupos químicos, os flavonoides que apresentam importante ação antioxidante. As farinhas do fruto de $H$. stigonocarpa apresentaram neste estudo quantidades expressivas de fenóis totais. Teores variáveis de compostos fenólicos são produzidos naturalmente como metabólitos secundários em vegetais. Os quantitativos fenólicos podem oscilar conforme a necessidade fisiológica do vegetal, sendo alguns motivos ligados ao estresse fisiológico, ataque por fitopatógenos, insetos ou animais herbívoros (Oliveira et al. 2016).

Os teores de antocianinas e flavonoides apresentaram resultados satisfatórios de 0,03; 0,08 e 0,01 mg $100 \mathrm{~g}-1$ para antocianinas e de 0,$21 ; 0,23$ e $0,27 \mathrm{mg} 100 \mathrm{~g}-1$ para flavonoides para as farinhas da casca, arilo e semente respectivamente do fruto de $H$. stigonocarpa. Estes valores podem ser avaliados resíduos devido à perda considerável destes compostos durante o processo de secagem farinácea Altas temperaturas influenciam negativamente no produto decompondo estes grupos de agentes antioxidantes. Conforme Ávila (2014), matérias-primas de origem vegetal que apresentam compostos antociânicos e flavonólicos podem sofrer com a termolabilidade.

Importantes teores de $\beta$-caroteno e licopeno foram obtidos neste estudo nas farinhas da casca, arilo e semente do fruto de H. stigonocarpa. Para o teor de $\beta$-caroteno foram obtidos resultados iguais a 42,53 e 68,71 $\mu \mathrm{g} 100 \mathrm{~g}^{-1}$ exceto na farinha da semente onde não houve detecção desta classe de composto. Teores de licopeno apresentaram resultados iguais a 31,00; 53,32 e 130,29 $\mu \mathrm{g} 100 \mathrm{~g}^{-1}$. Os compostos de $\beta$-caroteno e licopeno agem também como antioxidantes prevenindo a ação deletéria dos radicais livres no organismo. Como discutido anteriormente, as farinhas do fruto de $H$. stigonocarpa demonstram ser ótimas opções no desenvolvimento de produtos com aditivos bioativos naturais agregando qualidade aos novos produtos alimentícios e farmacêuticos.

$\mathrm{Na}$ Tabela 5 podem-se observar os resultados da capacidade de formação de gel farináceo para as farinhas do fruto de H. stigonocarpa.

Tabela 5. Capacidade de formação de gel farináceo das farinhas da casca, arilo e semente do fruto de Hymenaea stigonocarpa.

\begin{tabular}{lccccccc}
\hline Amostra & \multicolumn{7}{c}{ Formação de gel farináceo } \\
\cline { 2 - 8 } & $\mathbf{2 \%}$ & $\mathbf{6 \%}$ & $\mathbf{1 0 \%}$ & $\mathbf{1 4 \%}$ & $\mathbf{1 8 \%}$ & $\mathbf{2 2 \%}$ & $\mathbf{2 6 \%}$ \\
\cline { 2 - 7 } Casca & - & - & - & - & - & - & - \\
Arilo & - & - & \pm & + & + & + & + \\
Semente & \pm & \pm & + & + & + & + & + \\
\hline
\end{tabular}

Testes realizados em triplicata: (-) Ausência de gel; ( \pm ) Gel frágil e (+) Gel resistente

Na formação de gel resistente é possível observar bons resultados para a farinha da semente, mesmo em uma baixa concentração de $2 \%$, onde apresentou a formação de gel frágil. Em seguida observa-se a formação de gel para a farinha do arilo com gel resistente a partis da concentração de $10 \%$. Estas farinhas podem ser utilizadas na indústria alimentícia como matérias-primas na produção de alimentos que requerem forma pastosa como em mingaus e papas que possuem consistência firme. A farinha da casca do fruto de $H$. stigonocarpa não apresentou em nenhuma das concentrações a formação de gel.

Comparando os resultados obtidos neste estudo com os desenvolvidos por Santana et al. (2017), os autores obtiveram resultados próximos ao obtido pela farinha da semente de jatobá, para as farinhas de trigo branco, aveia A e $B$ onde obtiveram os melhores resultados de gelificação. A formação de gel é o resultado que ocorre através do arranjo 
tridimensional observado nos carboidratos modificados ou não, ocorrendo assim este fenômeno de gelificação através do processo de aquecimento (Adebowale \& Lawal, 2003).

\section{Conclusão}

Os resultados obtidos para as farinhas da casca, arilo e sementes do fruto de $H$. stigonocarpa apresentaram boas qualidades tanto física, físico-química, tecnológica, antioxidante, de fenólicos totais e carotenóides. Com estes resultados, sugere-se a utilização destas farinhas vegetais para a utilização para confeitaria e na indústria de alimentos que necessitam de matérias-primas que necessitam de formação de gel, bem como coadjuvantes em produtos nutracêuticos empregados na panificação, agregando valor ao produto com características bioativas importantes para a manutenção da saúde.

\section{Agradecimentos}

Ao Instituto Federal de Educação, Ciência e Tecnologia Goiano, Campus Rio Verde/GO; aos laboratórios Solotech Cerrado, de Nutrição Animal, Química Tecnológica; as instituições de fomento CAPES, CNPq e FAPEG pela bolsa de mestrado para o primeiro autor e de iniciação científica para a segunda e para o terceiro autor.

\section{Referências}

Adebowale, K. O., Lawal, O. S. (2003). Foaming, gelation and electrophoretic characteristics of mucuna bean (Mucuna pruriens) protein concentrates. Food Chemistry, 83, p. 237-246.

Albuquerque, J. G., Duarte, A. M., Conceição, M. L., \& Aquino, J. S. (2016). Integral utilization of seriguela fruit (Spondias purpurea L.) in the production of cookies. Revista Brasileira de Fruticultura, 38(3), p. 1-7.

Alcântara, S. R., Sousa, C. A. B., Almeida, F. A. C., \& Gomes, J. P. (2012). Caracterização físico-química das farinhas do pedúnculo do caju e da casca do maracujá. Revista Brasileira de Produtos Agroindustriais, 14, n. Especial, p. 473-478.

Alcarde, J. C., et al. (1992). Avaliação da higroscopicidade de fertilizantes e corretivos. Scientia Agricola, 49(1), p. 137144.

Ávila, B. P. (2014). Efeito dos processamentos nas propriedades tecnológicas, sensoriais e nutricionais de feijão comum e caupi e sua aplicação em panificação. (Dissertação de mestrado). Universidade Federal de Pelotas, Brasil.

Bastos, J. S., Martinez, E. A., \& Souza, S. M. A. (2016). Características físico-químicas da polpa de umbu (Spondias tuberosa Arruda Câmara) comercial: efeito da concentração. Journal Bioenergy and Food Science, 3(1), p. 11-16.

Botelho, S. A., Ferreira, R. A., Malavasi, M. M., \& Davide, A. C. (2000). Aspectos morfológicos de frutos, sementes, plântulas e mudas de jatobá-do-cerrado (Hymenaea stigonocarpa Mart. ex Hayne) - Fabaceae. Revista Brasileira de Sementes, 22(1), p. 144-152.

BRASIL - Resolução - CNNPA, no 12, de 1978. Comissão Nacional de Normas e Padrões para Alimentos, em conformidade com o artigo no 64, do Decreto-lei no 986, de 21 de outubro de 1969 e de acordo com o que foi estabelecido na 410aㅡ, 2003.

BRASIL. Ministério da Agricultura, Pecuária e Abastecimento. Instrução normativa $n^{\circ} 8,03$ jun. 2005. Regulamento Técnico de Identidade e Qualidade da Farinha de Trigo. Diário Oficial da República Federativa do Brasil, Brasília, DF, 03 jun. 2005, Seção 1, n. 105, p. 91.
Castilho, F., Fontanari, G. G., \& Batistuti, J. P. (2010). Avaliação de algumas propriedades funcionais das farinhas de tremoço doce (Lupinus albus) e feijão guandu (Cajanus cajan (L.) Millsp) e sua utilização na produção de fiambre. Revista Ciência e Tecnologia de Alimentos, 30(1), p. 68-75.

Cereda, M. P., \& Vilpoux, O. (2010). Metodologia para divulgação de tecnologia para agroindústrias rurais: exemplo do processamento de farinha de mandioca no Maranhão. Revista Brasileira de Gestão e Desenvolvimento Regional, 6(2): 219-250.

Clemente, E., Flores, A. C., Rosa, C. I. L. F., \& Oliveira, D. M. (2012). Características da farinha de resíduos do processamento de laranja. Revista Ciências Exatas e Naturais, 14(2), p. 257-269.

Correia, P., Leitão, A., \& Beirão-da-costa, M. L. (2009). The effect of drying temperatures on morphological and chemical properties of dried chestnut flours. Journal of Food Engineering, 90, p. 325-332.

Costa, A. P. F., Pinto, E. G., \& Soares, D. S. B. (2017). Obtenção da farinha do mesocarpo do pequi. Revista Agrarian, 10(38), p. 349-354.

Duarte, E. L., Carlos, L. A., Rodrigues, C. G., Andrade, R. M., \& Oliveira, K. G. (2017). Influência da liofilização sobre os carotenoides de frutos do cerrado e comportamento higroscópico dos produtos liofilizados. Revista Perspectivas Online, Ciências Biológicas e da Saúde, 23(7), p. 22-33.

Fasolin, L. H., Almeida, G. C., Castanho, O. S., \& Netto-Oliveira, E. R. (2007). Biscoitos produzidos com farinha de banana: avaliações química, física e sensorial. Revista Ciência e Tecnologia de Alimentos, 27(3), p. 524-529.

Ferreira, E. S., Lucien, V. G., Amaral, A. S., \& Silveira, C. S. (2008) Caracterização físico-química do fruto e do óleo extraído de tucumã (Astrocaryum vulgare Mart). Revista Alimentos e Nutrição, 19(4), p. 427-433.

Fertonani, H. C. R., et al. (2006). Influence of acid concentration on extraction and quality of apple pomace pectin. Semina: Ciências Agrárias, 27(4), p. 599-612.

Frabetti, A. C. C. (2017). Produção e caracterização de polpa de goiaba (Psidium guajava L.) em pó por Cast-Tape Drying. (Dissertação de mestrado). Universidade Federal de Santa Catarina, Brasil.

Garcia, D. M., Alencar, U. R., Mota, B. G., Borges, I. R., \& Souza, P. O. (2017). Determinação de características tecnológicas de farinhas produzidas a partir de resíduos de polpas de mamão, melão e goiaba e sua utilização na elaboração de biscoitos tipo cookies. ScientiaTec: Revista de Educação, Ciência e Tecnologia do IFRS, 4(1), p. 29-41.

Hiane, P. A., Bogo, D., Ramos, M. I. L., \& Ramos Filho, M. M. (2003). Carotenóides pró-vitamínicos A e composição em ácidos graxos do fruto e da farinha do bacuri (Scheelea phalerata Mart.). Revista Ciência e Tecnologia de Alimentos, 23(2), p. 206-209.

Hubinger, S. Z., Salgado, H. R. N., \& Moreira, R. R. D. (2009). Controles físico, físico-químico e microbiológico dos frutos de Dimorphandra mollis Benth., Fabaceae. Revista Brasileira de Farmacognosia, 19(3), p. 690-696.

INSTITUTO ADOLFO LUTZ. Normas analíticas do Instituto Adolfo Lutz. v. 1: Métodos químicos e físicos para análises de alimentos. $4^{\text {a }}$ Ed., 1ํㅡㄹ Ed., Digital, São Paulo: IMESP, 2008.

Júnior, W. F. N., \& Carvalho, A. C. (2018). Influência da ingestão prévia de carboidratos com alto e baixo índice glicêmico sobre o potencial aeróbico de corredores de rua. Revista Brasileira de Nutrição Esportiva, 12(72): 419-430.

Leonel, M., Freitas, T. S., \& Mischan, M. M. (2009). Physical characteristics of extruded cassava starch. Scientia Agricola, 66(4), p. 486-493.

Mendonça, L. M. V. L., Conceição, A., Piedade, J., Carvalho, V. D., \& Theodoro, V. C. A. (2006). Caracterização da composição 
química e do rendimento dos resíduos industriais do limão tahiti (Citrus latifolia Tanaka). Revista Ciência e Tecnologia de Alimentos, 26(4), p. 870-874.

Menezes Filho, A. C. P. de., Oliveira Filho, J. G. de., Christofoli, M., \& Castro, C. F. de. S. (2018). Atividade antioxidante, conteúdo de fenólicos totais, carotenoides e provitamina $\mathrm{A}$ em extratos vegetais do Cerrado goiano. Uniciências, 22(1), p. 28-32.

Nagata, M., \& Yamashita, I. Simple method for simultaneous determination of chlorophyll and carotenoids in tomatões fruit. (1992). Nippon Shokuhin Kogyo Gakkaoshi, 39(10), p. 925-928.

Oliveira, G. S., Costa, J. M. C., \& Afonso, M. R. A. (2014). Caracterização e comportamento higroscópico do pó da polpa de cajá liofilizada. Revista Brasileira de Engenharia Agrícola e Ambiental, 18(10), p. 1059-1064.

Queiroz, E. R., Abreu, C. M. P., Santos, C. O., \& Simão, A. A. (2015). Composição química e fitoquímica das farinhas da casca e da semente de lichias (Litchi chinensis Sonn) cultivar 'Bengal'. Revista Ciência Rural, 45(2), p. 329-334.

Rocha, M. S., Figueiredo, R. W., Araújo, M. A. da. M., \& MoreiraAraújo, R. S. dos. R. (2013). Caracterização físico-química e atividade antioxidante (in vitro) de frutos do cerrado piauiense. Revista Brasileira de Fruticultura, 35(4): 933941.

Rodrigues, G. M., \& Silva, C. (2017). Extração ácida da pectina da casca de maracujá assistida por ultrassom. Revista eXacta, 10(1), p. 45-52.

Santana, G. S., Oliveira Filho, J. G. de., \& Egea, M. B. (2017). Características tecnológicas de farinhas vegetais comerciais. Revista de Agricultura Neotropical, 4(2), p. 8895.

Santos, J. C., Silva, G. F., Santos, J. A. B., \& Júnior, A. M. O. (2010). Processamento e avaliação da estabilidade da farinha de banana verde. Revista Exacta, 8(2), p. 219-224.

Seibel, N. F., \& Beléia, A. P. (2009). Características químicas e funcionalidade tecnológica de ingredientes de soja [Glycine max (L.) Merrill]: carboidratos e proteínas. Brazilian Journal of Food Technology, 12(2), p. 113-122.

Silva, A. K. N., Abe, S. T. H., \& Santos, O. V. (2013). Processamento da farinha da casca do mangostão (Garcinia mangostana L.) com vistas aos aspectos nutricionais e de antocianina. Revista Brasileira de Tecnologia Agroindustrial, 7(02), p. 1074-1087.

Silva, M. R., Silva, M. S., Martins, K. A., \& Borges, S. (2001). Utilização tecnológica dos frutos de jatobá-do-cerrado e de jatobá-da-mata na elaboração de biscoitos fontes de fibra alimentar e isentos de açúcares. Revista Ciência e Tecnologia de Alimentos, 21(2), p. 176-182.

Silva-Sanchez, C., González-Castañeda, J., De León-Rodríguez, A., \& Barba de la Rosa, A. P. (2004). Functional and rheological properties of amaranth albumins extracted from two mexican varieties. Plant Foods for Human Nutrition, 56, p. 169-174.

Souza RLA, Correia RTP. (2013). Caracterização físico-química e bioativas do figo-da-Índia (Opuntia fícus-indica) e farinha de algaroba (Prosopis juliflora) e avaliação sensorial de produtos derivados. Revista Alimentos e Nutrição, 24(4), p. 369-377.

Souza, J. M., Palvares, V. S., Leite, F. M. N., Reis, F. S., \& Felisberto, F. A. V. (2008). Caracterização físico-química de farinhas oriundas de variedades de mandioca utilizadas no vale do Juruá, Acre. Acta Amazônica, 38(4), p. 761-766.

Souza, M. W. S., Ferreira, T. B. O., \& Vieira, I. F. R. (2008). Composição centesimal e propriedades funcionais tecnológicas da farinha da casca do maracujá. Revista Alimentos e Nutrição, 19(1), p. 33-36.

Shaw, D. The solid-liquid interface. (1992). Introduction to colloid surface chemistry. In A. $4 \underline{a}$ Ed., Cap. 6, (pp. 151-
159). Grã-Bretanha, Reed Educational and Professional Publishing. 